\title{
ESTUDO DA TUTELA COLETIVA SOBRE OS DIREITOS TRANSINDIVIDUAIS
}

\section{ARTIGO ORIGINAL}

RIBEIRO, Danilo Miranda ${ }^{1}$

RIBEIRO, Danilo Miranda. Estudo da tutela coletiva sobre os direitos transindividuais. Revista Científica Multidisciplinar Núcleo do Conhecimento. Ano. 06, Ed. 12, Vol. 02, pp. 152-167. Dezembro de 2021. ISSN: 2448-0959, Link de acesso:https://www.nucleodoconhecimento.com.br/lei/direitos-transindividuais

\section{RESUMO}

Este trabalho busca construir uma análise jurídica sobre os elementos do processo coletivo para proteção dos direitos transindividuais no ordenamento jurídico do Brasil. Em razão de ter suas disposições em leis espaçadas, o estudo da tutela coletiva se depara com o problema de um sistema hermético e de difícil compreensão. Com o objetivo de abrir caminho ao estudo do processo coletivo e afastar tal problema, a presente pesquisa tem como problemática a discussão sobre os principais elementos do processo coletivo, visando demonstrar que se trata de um sistema processual coerente e harmônico. A metodologia utilizada será revisão bibliográfica. Dessa maneira, o trabalho apresenta como resultado a sistematização de itens fundamentais à compreensão da tutela coletiva, ao abordar as disposições legais e doutrinárias sobre a proteção aos direitos transindividuais, de forma a abrir campo para uma compreensão da tutela coletiva.

Palavras-chave: Processo Coletivo, Direitos Transindividuais, Processo Civil, Princípios.

\footnotetext{
${ }^{1}$ Mestrando em Direitos Humanos e Democracia pela UFPR-Universidade Federal do Paraná. Bacharel em Direito pela UCSal-Universidade Católica do Salvador. ORCID: https://orcid.org/0000-0001-6503-9625
} 


\section{INTRODUÇÃO}

A tutela coletiva constitui um instrumento processual essencial à concretização da justiça social, ao proteger bens jurídicos que não pertencem a apenas a um indivíduo, mas dizem respeito à coletividade. Acontece que as disposições legais sobre o instituto estão localizadas em legislações variadas e não dispensam o entendimento constitucional da matéria, o que pode ser um obstáculo à investigação coerente do processo coletivo. Em consideração a tal problema, a presente pesquisa tem como objetivo oferecer uma reflexão sobre os elementos essenciais da proteção coletiva aos direitos transindividuais, como o conceito dos direitos transindividuais, legitimidade e competência. Dessa maneira, o processo coletivo será apresentado de uma forma coerente e harmônica com os princípios constitucionais norteadores, de modo a afastar o hermetismo que pode ser percebido ao conhecer a tutela coletiva. A metodologia utilizada será a revisão bibliográfica de autores que entregaram uma contribuição importante à compreensão da proteção aos direitos transindividuais.

Sob o prisma constitucional, o princípio do devido processo legal (art. 5ำ, LIV, CF/88) deve ser interpretado por sua dimensão coletiva, ao almejar a redução dos formalismos para entregar ao jurisdicionado um processo metaindividual efetivo e justo. O sistema processual coletivo atribui a legitimidade a diversas entidades (ope legis), uma vez que a relevância dos interesses tutelados evoca a responsabilidade de diversos atores para assegurar os direitos de uma coletividade. Nesse sentido, o art. 103, do CDC coloca a eficácia erga omnes ou ultra partes para as decisões prolatadas no bojo do processo coletivo (BELLINETTI; SOUZA, 2019).

Quanto à classificação, Zavascki (2005, p. 18) divide os interesses tutelados coletivamente em duas categorias. Os primeiros seriam os interesses individuais homogêneos, que teriam seu caráter coletivo por uma questão empírica, contingencial, não necessária, no qual existiriam vários sujeitos, porém o objeto é divisível. A segunda categoria abrangeria os interesses difusos e coletivos, constituídos por aqueles que são coletivos por sua essência, que dizem respeito a um objeto indivisível e a um número incerto de sujeitos. Em relação aos interesses 
transindividuais é possível concebê-los em duas áreas separadas: os direitos individuais homogêneos e os direitos coletivos stricto sensu e difusos.

Segundo Ronaldo Santos (2014), a ideia de proteção ao direito da coletividade é para garantir a justiça social de grupos sociais ofendidos ou para judicializar situações que antes não tinham a proteção judiciária. Para o autor, a ação coletiva teve como antecedente o Bill of Peace, que remonta a história do século XVII:

[...] tratava de uma autorização para o processamento de uma ação individual sob a forma coletiva, concedida nas hipóteses em que o autor requeria que o provimento da demanda englobasse os direitos de todos os indivíduos que estivessem em igual condição de litígio, para que a questão fosse tratada de modo uniforme e com vistas a evitar a multiplicação de processos (SANTOS, 2014, p. 238).

Com ênfase na relação dos direitos transindividuais como os direitos fundamentais, Hachem entende que os primeiros ostentam os mesmos elementos que seriam relacionáveis aos direitos fundamentais das três gerações, não apenas da terceira, segunda ou primeira geração:

Por conta da complexidade de sua natureza jurídica e estrutura normativa, todos os direitos fundamentais reúnem concomitantemente a totalidade dos traços que supostamente seriam peculiares a cada uma das gerações: (i) impõem deveres negativos ao Estado; (ii) dirigem ao Poder Público obrigações de fornecer prestações fáticas e normativas; (iii) ostentam a titularidade transindividual alegadamente exclusiva dos "direitos de terceira geração", bem como, simultaneamente, a titularidade individual pretensamente típica dos "direitos de primeira e segunda geração" (HACHEM, 2013, p. 621).

Por intermédio das demandas coletivas, amplifica-se o acesso à justiça de uma coletividade indeterminada ou um grupo determinado de pessoas. Aponta-se como benefícios dessas ações a socialização e democratização do processo, com a concretização de direitos e a alteração da realidade social; a possibilidade de correção de um ilícito que não seria postulado em uma demanda individual diante de seu ínfimo valor particular, mas que coletivamente possui um grande impacto social; a igualdade entre os litigantes; a molecularização da demanda e concretização do princípio da segurança jurídica e confiança legítima diante de decisões uniformes para casos similares; a redução de demandas no poder judiciário, dentre muitos outros. 
Mais especificamente, os interesses individuais homogêneos vestem a roupagem de interesses individuais, porém, ante certas configurações da sociedade, surge a necessidade de serem tutelados coletivamente. A própria nomenclatura já traduz parte do conceito do referido interesse, conforme lição de Zavascki:

$\mathrm{Na}$ verdade, a própria denominação interesses individuais homogêneos já exibe dois enunciados: de um lado, trata-se de interesses ontologicamente individuais, não coletivos; de outro lado, que consistem numa multiplicidade de interesses individuais apresentando um determinado grau de uniformidade ou homogeneidade, sua característica mais importante (ZAVASCKI, 2005, p. 18).

Consoante o art. 81, da Lei 8.078/91, os interesses individuais homogêneos se fundam na ideia de origem comum, no fato lesivo que afetou e violou inúmeras pessoas em sua individualidade, não havendo exigência de relação jurídica base entre os titulares ou entre as partes, nem uma unidade quanto ao fato ou à temporalidade (ZAVASCKI, 2005, p. 21).

Os interesses individuais homogêneos são aqueles que têm em sua origem um fato lesivo que afetou uma coletividade e supera a esfera do interesse individual. Logo, esses direitos têm uma procedência comum, que surgem em conduta omissiva ou comissiva da parte adversa que afeta direitos que fogem ao mero aspecto individual e criam a pretensão coletiva, trazendo à discussão questões superiores à mera lide singular.

Conforme lição de Zavascki (2005, p. 21), são divisíveis, apropriáveis individualmente, disponíveis, transmissíveis e representáveis em juízo pelo próprio titular, episodicamente transindividuais, subjetivamente determinados e diretamente reparáveis.

No entanto, a característica de individualidade não afasta o eminente teor transindividual dos direitos individuais homogêneos. Quando coletivamente considerados, estes direitos ultrapassam em muito a esfera de interesse particular de seus titulares. A característica coletiva não reside na impossibilidade de serem apropriados individualmente ou de seus titulares serem indetermináveis, mas no 
alcance que a violação à sociedade revela (ZAVASCKI, 2005, p. 21-22). A lesão aos interesses individuais homogêneos viola a paz social e promove um grande desconforto social, o que gera um efeito sinérgico, vez que ambos se reforçam.

Inclusive, seria possível a denominação de interesses individuais relevantes ou de origem comum, o que não foi feito em razão da homogeneidade ser imprescindível para a oportunidade de tutelar coletivamente o direito (ZAVASCKI, 2005, p. 19).

Ainda em relação aos direitos transindividuais, surgem as categorias de direitos difusos e coletivos stricto sensu. Primeiramente, os direitos difusos são aqueles interesses coletivos que são indivisíveis, cujos titulares são indetermináveis e não ostentam relação jurídica entre eles (DIDIER JUNIOR; ZANETI JUNIOR, 2014, p. 7678). O conceito dos direitos difuso é encontrado pela análise do art. 81, I, do Código de Defesa do Consumidor, que são conceituados como interesses transindividuais de natureza indivisível, cujos titulares são indeterminados e conectados por um fato comum.

Os direitos difusos são aqueles que pertencem a uma coletividade de sujeitos que são indeterminados, ostentam direito de natureza indivisível e são ligados por uma situação de fato (superveniente). Ou seja, a relação entre os titulares surgiu em momento posterior à lesão, vez que inexistia qualquer vínculo entre os lesionados em momento pretérito ao fato que deu causa à tutela coletiva (DIDIER JÚNIOR; ZANETI JÚNIOR, 2014, p. 78).

Em seguida, existem os direitos coletivos stricto sensu, que encontram definição no art. 81, II do CDC. Eles são direitos transindividuais, com a diferença de que seus titulares são certos grupos definidos de pessoas, ou seja, existe uma relação jurídica base entre os titulares, que são indeterminados, mas determináveis. Ou seja, a diferença entre os direitos difusos e os coletivos stricto sensu é que os primeiros têm a titularidade indeterminada e os segundos têm como titulares certas categorias coletivas, logo as pessoas podem ser determinadas (DIDIER JÚNIOR; ZANETI JÚNIOR, 2014, p. 78-79). 
Para os interesses coletivos stricto sensu é primordial que se identifique qual foi o grupo de indivíduos que foi lesado, posto que o direito é indivisível e os titulares são aqueles que pertencem a certa categoria (DIDIER JÚNIOR; ZANETI JÚNIOR, 2014, p. 78).

Vale destacar que a relação jurídica base deve ser anterior ao acontecimento do fato lesivo. Isto é, a relação jurídica entre os titulares não advém do dano, como ocorre nos direitos difusos, mas em razão de aderência à categoria trabalhista, associação, determinada sociedade e outras causas pretéritas à lesão (DIDIER JÚNIOR; ZANETI JÚNIOR, 2014, p. 78). Nestes moldes, os titulares do direito são plenamente determináveis e pertencem a uma coletividade que é individualizável.

\section{LEGITIMIDADE}

Nas situações de jurisdição singular, quase sempre, os temas em comento interessam apenas às partes envolvidas na lide, sem ter qualquer peso direto sobre as pessoas que não estejam envolvidas no polo passivo ou ativo da lide.

Tradicionalmente, a legitimidade ativa da tutela de interesse individual reclama um exame de titularidade e remonta o legado do Direito Romano (DIDIER JÚNIOR; ZANETI JÚNIOR, 2014, p. 79). Já o instituto de pleitear direito em nome de outrem não é algo muito mais atual, posto que "[...] na Idade Média, não havia ainda o conceito de personalidade jurídica, de modo que nem sequer era possível cogitar de alguém estar sendo representado por outra pessoa; a legitimidade ordinária era a regra absoluta" (ZAVASCKI, 2005, p. 11).

No ordenamento jurídico brasileiro a regra geral é disposta no art. 18, do Código de Processo Civil, que coloca a titularidade do direito como requisito fundamental à sua discussão, vez que resta vedado a discussão de direito que pertence a pessoa alheia, ressalvados os casos que estejam expressamente previstos na lei.

No entanto, além da legitimidade ordinária, retratada pelo art. 18, do CPC, existe, em caráter excepcional, a legitimidade ativa extraordinária, que é admitida em casos previstos expressamente pela lei, em que alguém irá pleitear direito em nome do 
titular. Neste caso, há uma opção legislativa sobre os casos em que será possível invocar em juízo o direito de outrem.

Fora os casos previstos pelo corpo legal, há que se considerar as hipóteses de legitimidade extraordinária como consequência lógica do sistema jurídico. Neves (2016) é um dos autores que tecem comentários sobre a possibilidade de legitimidade extraordinária quando ausente permissão legal expressa:

Apesar de o art. 18, caput, do Novo CPC prever que a legitimação depende de autorização expressa da lei, a melhor doutrina entende que, além da previsão legal, também se admite a legitimação extraordinária quando decorrer logicamente do sistema, como acontece com a legitimação recursal do advogado em apelar do capítulo da sentença que versa sobre seus honorários advocatícios (NEVES, 2016, p. 188).

A flexibilização em relação à regra do art. 18, do CPC, aparece como melhor molde à efetividade do instituto, próprio para a defesa dos interesses da coletividade. Porém, adverte-se: a flexibilização não traz como acompanhamento inevitável um procedimento mais simples.

É perceptível que o mesmo direito pode ser garantido a pessoas dos mais diferentes grupos sociais, o que ocorre com certa frequência, a exemplo de quando há violação de garantias sociais. Logo, surge uma dificuldade em afirmar que há uma legitimidade para representar todos os interessados, ante a grande diferença cultural, social ou econômica que existe entre os titulares de direito em demandas coletivas.

Foi nesse contexto (ZAVASCKI, 2005, p. 15) que começaram as dificuldades da defesa dos interesses coletivos. Se os indivíduos são diferentes, como pressupor que um deles tem legitimidade para demandar por todos na defesa desse interesse comum? Como estender os efeitos da tutela coletiva sobre os que não estiverem em juízo, se não se pode pressupor qual o legítimo interesse desses outros? Como exigir que grandes grupos compareçam em juízo? Como fazer isso se os membros do grupo nem sequer são determinados? 
Ante a indeterminação dos titulares, grande diferença que existe entre eles e a dificuldade prática de todos levarem certas questões a juízo, justifica-se a legitimação de entidades que tenham como finalidade a busca e defesa dos interesses de uma coletividade.

Nestes moldes, os legitimados coletivos não são titulares dos direitos que são legitimados para pleitear e os titulares daqueles direitos têm a titularidade ativa esvaziada (NEVES, 2016, p. 189). Por excelência, na letra de Zavascki (2005, p. 15), a legitimidade ativa nas demandas coletivas poderia ser nomeada como a representação dos ausentes.

$\mathrm{Na}$ jurisdição coletiva, inexiste vínculo direto entre a titularidade do direito e a legitimidade, mas há situação jurídica que traz aptidão a certas instituições para defenderem os interesses que não se restringem à ideia de individualismo, o que traz a configuração da legitimidade extraordinária. Neste sentido:

A legitimação ao processo coletivo é extraordinária: autoriza-se um ente a defender, em juízo, situação jurídica de que é titular um grupo ou uma coletividade. Não há coincidência entre o legitimado e o titular da situação jurídica discutida (DIDIER JUNIOR; ZANETI JUNIOR, 2014, p. 21).

O ordenamento jurídico brasileiro acolheu a opção de presumir a capacidade de certas instituições a serem legitimadas à defesa das demandas coletivas (ZAVASCKI, 2005, p. 102). Ou seja, os legitimados para a propositura de ações coletivas surgem do estabelecimento legal, como ocorre no art. 5ํ da Lei da Ação Civil Pública, que elenca o Ministério Público, Defensoria Pública, União, os Estados, o Distrito Federal, os Municípios e outros sujeitos, como representantes da coletividade e aptos a ajuizarem ação civil pública.

No mesmo movimento da LACP, o art. 82 do Código de Defesa do Consumidor destaca a legitimidade ativa do Ministério Público, União, Estados e Municípios, autarquias, empresas públicas, fundações, sociedades de economia mista ou por associação para defender os direitos difusos, coletivos ou individuais homogêneos dos consumidores. 
Ainda, em relação à legitimidade ativa para a propositura das ações coletivas, Zavascki (2005, p. 132) levanta aspecto polêmico que rodeia a possibilidade de o Ministério Público defender os interesses individuais homogêneos, já que a CRFB/88 não confere essa função ao parquet.

O vernáculo constitucional, em seu art. 129, inciso III, não elenca a defesa dos interesses individuais homogêneos como uma das atribuições do Ministério Público, que tem suas atividades vinculadas ao texto constitucional. Dessa forma, é possível interpretar como vedação legal a falta de determinação para defender os referidos interesses (ZAVASCKI, 2005, p. 132).

Outros, advogam pela legitimidade irrestrita do Ministério Público (ZAVASCKI, 2005, p. 133). Consoante o art. 129, inciso IX, da CRFB/88, é função do MP o exercício de funções compatíveis à sua finalidade, o que engloba a defesa dos interesses sociais e individuais indisponíveis, à luz do art. 127, da CRFB/88. Para esta corrente, os interesses transindividuais possuem presunção de relevância social, o que permite a atuação do parquet (ZAVASCKI, 2005, p. 133).

Por fim, há a tese da legitimidade restrita, que surge como uma consequência da ideia de que o Ministério Público teria legitimidade irrestrita, com a advertência de que os assuntos de relevância social só poderiam ser aqueles que comportarem congruências com as funções constitucionais do parquet (ZAVASCKI, 2005, p. 132), isto com base no art. 127, da CRFB/88, sem que o esforço de presumir relevância seja capaz de trazer a legitimidade ao Ministério Público.

Sobre a legitimidade do Ministério Público em tutelar interesses individuais homogêneos, Zavascki conclui que a resposta para tal pergunta se encontra através da análise do figurino legal, pois é na lei que reside o conceito do interesse de relevância social, que assegurará a legitimidade ativa do parquet (ZAVASCKI, 2005, p. 132). Nestes moldes, Zavascki leciona que os interesses de relevância social são constituídos pela: "imposição da indisponibilidade, a atribuição direta de legitimidade ao Ministério Público para sua defesa e a caracterização expressa de relevância social" (ZAVASCKI, 2005, p. 136). 
O deslinde é incontroverso. Ausente o aspecto da relevância social retratado por Zavascki, não há que se falar em legitimidade do parquet para atuar em defesa dos interesses individuais homogêneos.

Por fim, vale destacar as características que Didier revela na legitimação coletiva ativa, como regulação pelo art. 5ำ da Lei Federal oㅜ 7.347/85 e do art. 82 do CDC, ser ostentada por entidades que não atua em seu próprio nome, vez que os titulares não possuem capacidade postulatória:

\begin{abstract}
Enfim, o certo é que a legitimação coletiva possui as seguintes características: a) está regulada, inicialmente, por lei (art. 5ำ da Lei Federal no 7.347/85; art. 82 do CDC etc.); b) é conferida a entes públicos, privados e despersonalizados, e, até, ao cidadão, na ação popular; c) o legitimado coletivo atua em nome próprio na defesa de direitos que pertencem a um agrupamento humano (pessoas indeterminadas, comunidade, coletividade ou g rupo de pessoas, titulares de direitos individuais abstratamente considerados, na forma do a1i. 81 do CDC e seus incisos); d) esse agrupamento humano não tem personalidade judiciária, portanto não pode atuar em juízo para proteger os seus direitos, 26 cuja defesa cabe aos legitimados coletivos, que possuem legitimação autônoma, exclusiva e concorrente e simples (DIDIER JUNIOR; ZANETI JUNIOR, 2014, p. 212).
\end{abstract}

\title{
3. COMPETÊNCIA
}

A competência é elemento fundamental para a satisfação do devido processo legal. A defesa dos direitos transindividuais ocorre em prol de uma coletividade, que pode estar separada e sem qualquer vínculo que a una, o que traz atenção ao momento de fixação da competência.

Para a fixação da competência territorial nas demandas coletivas, Neves elenca sete etapas necessárias à revelação do juízo competente. Ressalta-se que a fixação da competência territorial é consequência da análise da legislação processual, à mesma maneira que se faz nos casos de tutelas singulares, posto que é matéria vinculada à lei tratada de forma isonômica à tutela individual (NEVES, 2016, p. 168).

Porém, é necessário destacar que a legislação que regula a tutela dos direitos coletivos pode estabelecer a competência originária de certos tribunais ou órgãos 
atípicos, à amaneira do que pode ocorrer no processo coletivo especial, ação popular, ação civil pública, mandado de injunção coletivo, mandado de segurança coletivo e ação de improbidade administrativa.

Pela relevância das medidas, vale destacar que a competência no âmbito coletivo é regulada pelos arts. 2ㅜ da Lei da Ação Civil Pública, e 93, do Código de Defesa do Consumidor, que fixam como critério de competência territorial o local do dano.

Ainda, consoante a legislação da LACP, a competência seria territorial e funcional, o que levanta o debate se a competência seria em razão do foro, pela questão territorial, ou da maior eficácia e facilidade, em virtude do critério funcional. Não obstante, é certo que a competência territorial é absoluta, o que conduz ao seu respeito obrigatório.

Após a determinação do foro competente, se inicia a busca pelo juízo competente, o que será feito a partir das leis de organização do poder judiciário e pelo CPC. Isto porque a competência do juízo é afetada pela competência territorial, jamais o inverso (NEVES, 2016, p. 186).

\section{EXECUÇÃO DE SENTENÇA PROFERIDA EM AÇÕES COLETIVAS}

O fundamento da execução de sentença individual é vestido pelo cumprimento de sentença coletiva, que deve ocorrer como continuação do processo de conhecimento, após o momento em que o devedor não tenha cumprido o comando sentencial. Darse-á cumprimento à fase de execução através do cumprimento de sentença, consoante inteligência das hipóteses previstas no art. 515, do CPC.

Em relação aos direitos difusos e coletivos stricto sensu a tutela do direito material será feita através da execução coletiva, que se desdobrará em benefício da comunidade, o que será feito através dos aspectos utilizados na execução individual, sem qualquer especialidade procedimental em razão da natureza coletiva do interesse (NEVES, 2016, p. 392-393).

Da execução pode surgir uma tutela inibitória (proibição da ilegalidade) ou reparatória in natura, como reversão dos danos, ou em dinheiro, que, neste caso, deve ser 
revertida para a pessoa jurídica de direito público que enfrentou a lesão ou para o Fundo de Direitos Difusos (art. 13 da Lei Federal no 7.347/1985) (DIDIER JÚNIOR; ZANETI JÚNIOR, 2014, p. 412).

Quanto à legitimidade, qualquer parte integrante do polo ativo pode promover a execução, mesmo que não tenha participado da fase de cognição, conforme interpretação do art. 15 da Lei 7.347, que elenca como requisito o lapso temporal de 60 dias do trânsito em julgado para que novos sujeitos adentrem ao processo com fins de iniciar a etapa de execução (DIDIER JÚNIOR; ZANETI JÚNIOR, 2014, p. 413). Ou seja, a execução coletiva de direitos difusos ou coletivos stricto sensu pode ser feita por qualquer legitimado extraordinário, respeitando o percurso temporal do trânsito em julgado. Isto também está disposto no art. 15 do CBPC-IBDP e art. 26 do CBPCUERJ/UNESA.

Ressalta-se a obrigatoriedade de propositura de cumprimento de sentença como atribuição essencial ao parquet, em cuidado dos interesses coletivos (NEVES, 2016, p. 391).

Porém, cabe distinguir que a obrigação do Ministério Público para executar sentença em ação civil pública surge após 60 dias do trânsito em julgado da sentença condenatória, consoante art. 15, da Lei 7.347/85.

Já, em relação à ação popular, surge o dever de o Ministério Público executar a sentença condenatória quando o cidadão se mostrar inerte por mais de 60 dias, contados a partir da publicação do acórdão de segundo grau, consoante art. 16, da Lei 4.717/65. Ou seja, haveria o dever funcional do parquet em movimento ao cumprimento de sentença provisória, ante a possibilidade de modificação do comando sentencial.

Por conseguinte, há, também, possibilidade de execução individual na execução dos direitos difusos e coletivos stricto sensu, conforme lição de Didier:

É também possível que a sentença proferida em um processo em que se discutem direitos difusos ou coletivos seja utilizada por um indivíduo corno título de uma execução individual, tendo em vista a extensão in 
utilibus da coisa julgada coletiva ao plano individual, já examinada. Obviamente, antes de executar a decisão, o indivíduo deverá proceder à liquidação do seu crédito, em que deverá demonstrar, inclusive, que é titular de um crédito (liquidação com thema decidendum mais amplo do que a liquidação individual prevista no CPC, restrita à decisão sobre o valor ou sobre a coisa a ser executada) (DIDIER JUNIOR; ZANETI JUNIOR, 2014, p. 415).

Quanto aos direitos individuais homogêneos, que são direitos individuais agregados por sua origem em comum, a execução será feita individualmente pelos titulares. Ou seja, o forte componente de coletividade que existia na fase de conhecimento se abrandou na fase de execução, vez que o interesse individual será tratado como coletivo na fase de execução (NEVES, 2016, p. 394). Quanto ao foro, o art. 516, do CPC impõe regra cogente, critério de competência absoluta, o que levaria o cumprimento de sentença para o juízo que decidiu a causa no primeiro grau de jurisdição.

A interpretação do referido dispositivo legal abarca a execução individual de sentença coletiva, porém, por critérios de praticidade Neves (2016, p. 376) defende como competente para liquidação individual de sentença coletiva o foro do domicílio do liquidante, para que não haja uma grande concentração de processos na comarca que decidiu sobre o caso em primeiro grau de jurisdição e menor onerosidade ao exequente.

Porém, cabe destacar que houve veto presidencial em relação ao parágrafo único do art. 97 do CDC, que obsta a hipótese de o foro da execução de sentença coletiva ser escolhido como o do domicílio do exequente.

Conforme Zavascki (2005, p. 164), não há como considerar o veto inútil, já que ele abre campo à interpretação e revela motivos que devem ser considerados, vez que ponderados pelos legisladores.

Ante a expressa fixação do foro competente para o cumprimento de sentença ser o do juízo que julgou a causa em primeiro grau de jurisdição, conforme art. 516, II do CPC, as dúvidas sobre a competência inexistem. 
Por derradeiro, há ponto controverso no art. 98 do $C D C$, em relação à possibilidade do Ministério Público e órgãos públicos (legitimados do art. 82 do $C D C$ ) promoverem a execução dos interesses individuais homogêneos, já que a esfera coletiva está esvaziada no momento da execução de interesses individuais. Com destaque, a lição de Zavascki:

Quanto ao Ministério Público e órgãos públicos, não se vislumbra circunstância na qual tais entes teriam algum interesse em promover liquidação e execução específicas em favor de particulares, ainda mais mediante representação. Em consequência, é certo não possuir - Ministério Público legitimidade para promover o tratamento individualizado da sentença genérica, mas não porque ele não tem poderes para agir em nome próprio em favor das vítimas e sucessores e sim porque, nessa hipótese, não se trata de defesa de interesses sociais ou individuais indisponíveis (ZAVASCKI, 2005, p. 163).

Por fim, é interessante notar que mesmo quem não faz parte do processo pode reclamar pelo que foi prolatado em sentença coletiva, já que seu objetivo é dar concretude aos direitos da coletividade:

Diante disso, os instrumentos processuais utilizados para tutela dos interesses transindividuais devem ser adaptados à natureza do interesse substancial em questão, de modo a lhe proporcionar uma maior efetividade. Para tanto, algumas alterações legislativas foram feitas com a finalidade de atender esse escopo. Dentre elas menciona-se a tratativa dada à sentença coletiva, à coisa julgada e à execução de sentença coletiva. A sentença coletiva, dada sua natureza, possui um alcance diferenciado no que se refere aos indivíduos por ela albergados, podendo atingir, in clusive, aquele que não foi parte no processo, dada a extensão secundum eventum litis da coisa julgada coletiva ao plano individual (ALFREDO, BALEOTI, 2012, p. 435).

\section{TUTELAS DE URGÊNCIA EM AÇÕES COLETIVAS}

No geral, a tutela de urgência em ações coletivas não apresenta divergência de fundamentação em relação às ações individuais (DIDIER JÚNIOR; ZANETI JÚNIOR, 2014, p. 342), o que traz incidência do CPC quando houver os requisitos dispostos em seu art. 300 .

Porém, existem certos procedimentos especiais que preveem esta técnica procedimental, como o art. 12, da LACP, que oportuniza a concessão da tutela 
antecipada na defesa de determinados interesses coletivos (DIDIER JÚNIOR; ZANETI JúNIOR, 2014, p. 342).

Como exemplo, também, o art. $4^{\circ}$ da LACP prevê a possibilidade de medida cautelar com o escopo de impedir danos aos bens jurídicos ali descritos. Acertadamente, Didier conduz à correção do disposto no referido artigo, vez que a medida teria caráter satisfativo, pois concederia o direito que se busca através da provocação do poder judicante, não uma medida cautelar:

\footnotetext{
Embora mencione expressamente a tutela cautelar, a redação do dispositivo não dá margem a dúvida: não se trata de tutela cautelar, mas, sim, tutela inibitória, que é satisfativa e visa exatamente obter providência judicial que impeça a prática de ato ilícito e, por consequência, a ocorrência de um dano (DIDIER JÚNIOR; ZANETI JÚNIOR, 2014, p. 343).
}

Importa destacar certos impedimentos à concessão da tutela provisória nas ações coletivas, como o disposto no art. $2^{\circ}$ da Lei Federal $n^{\circ}$ 8.437/1992 e $\S 2^{\circ}$ do art. 22 da Lei n. 12.016/2009, que limitam a concessão de liminar em mandado de segurança coletivo ou ação civil pública à realização de audiência do representante judicial da pessoa jurídica de direito público, devem ser realizados em prazo máximo de 72 horas.

Também, é parecido o que ocorre para a concessão de liminar no litígio coletivo pela posse de imóvel, que se condiciona ao preenchimento dos requisitos expostos no art. 565 do Código de Processo Civil.

\section{RECORRIBILIDADE NAS AÇÕES COLETIVAS}

Inexiste meio recursal específico para uso nas ações coletivas. O que há são excepcionais menções da recorribilidade na aplicação nas demandas coletivas, o que traz aplicação geral do sistema recursal do Código de Processo Civil (NEVES, 2016, p. 324)

Com relação à impugnação de decisão interlocutória, o art. 1.015 do CPC elenca o rol das hipóteses que abrem margem à interposição de agravo de instrumento. Consoante permissão expressa do referido artigo, em seu inciso XIII, outros casos 
previstos em lei permitem o manejo do agravo de instrumento, no que surge o art. 19, $\S 1^{\circ}$, da Lei 4.717/65, com a previsão de que cabe agravo de instrumento em razão de decisão interlocutória em sede de ação popular.

Conforme Neves (NEVES, 2016, p. 325), por força do microssistema coletivo, a supracitada norma deveria ter aplicação em todas as outras ações coletivas, o que possibilitaria a interposição de agravo instrumento em toda decisão interlocutória que surgisse em processo coletivo.

No que se refere à legitimidade recursal, interessa analisar que existem exceções à regra do 996 do CPC, que estabelece a parte vencida, terceiros interessados e Ministério Público como legitimados ativos à interposição de recursos.

Cabe frisar que a o art. 996 do CPC trata do interesse recursal e não da legitimidade recursal, vez que, ao tratar de parte vencida, acaba por se fazer uma análise relativa à sucumbência, o que leva à uma análise concreta da decisão que questiona o interesse recursal (NEVES, 2016, p. 330). A legitimidade nada tem a ver com o interesse, pois é parte legítima para recorrer àquele que ganha ou perde, o critério de fixação de legitimidade é totalmente independente do conteúdo da decisão.

Vale destacar importante tema: de acordo com a regra do art. 19, $\S 2^{\circ}$, da Lei 4.717/65, qualquer cidadão poderá recorrer das sentenças e decisões proferidas no bojo da ação popular. Acontece que, consoante a regra disposta no art. 996 do CPC, o cidadão que não compõe o polo ativo da lide não se encaixa como parte vencida nem em terceiro prejudicado, uma vez que o direito em comento na ação popular é difuso, o que afasta o conceito de terceiro interessado do parágrafo único, do art. 996, do CPC. Dessa forma, o cidadão não compõe o rol de sujeitos que tem legitimidade recursal, mas encontra permissão na LAP para recorrer.

Quanto aos efeitos recursais (obstativo, translativo, expansivo, substitutivo, regressivo e diferido) não há qualquer particularidade quando gerados no processo coletivo. Apenas quanto ao efeito suspensivo, há que se analisar a legislação atinente a cada 
ação, para que se verifique a ausência ou presença de cada efeito recursal referido (NEVES, 2016, p. 332).

Vale destacar a legislação que rege a Ação Civil Pública, que oportuniza ao juiz conferir efeito suspensivo aos recursos com o escopo de afastar dano irreparável às partes, consoante art. 14 da Lei 7.347/1985, o que formou o entendimento de que os recursos proferidos no bojo da Ação Civil Pública não têm efeito suspensivo apenas em razão de sua mera interposição (NEVES, 2016, p. 332). Dessa forma, a apelação que, por regra geral, tem efeitos suspensivos, em virtude do art. 1.012 do Código de Processo Civil, precisa cumprir os requisitos elencados no art. 14 da LACP (evitar dano irreparável à parte) para impedir que a sentença proferida em Ação Civil Pública gere efeitos imediatos.

\section{CONSIDERAÇÕES FINAIS}

Em face da discussão realizada por este trabalho, é possível observar que o texto da CRFB/88 ganha força e efetividade com a tutela dos direitos coletivos, à maneira de uma busca pela materialização das garantias sociais que estão previstas no vernáculo constitucional e podem ser reivindicadas judicialmente.

Tal instrumento é extremamente interessante para que a justiça social seja efetivada em uma sociedade de massa, onde a violação de um direito pode ultrapassar a esfera individual e atingir uma coletividade de pessoas. Com tal motivo em consideração, visando responder à problemática apresentada inicialmente, o viés constitucional de garantia aos direitos transindividuais foi posto em evidência ao conferir unicidade às disposições legais, que buscam assegurar os direitos coletivos em confluência à consecução do princípio da justiça social e do devido processo legal.

Ao explorar os elementos essenciais da tutela coletiva, foi apresentado um sistema harmônico e que encontra coerência para garantir a proteção ao bem jurídico de toda a coletividade. Desse modo, foi ultrapassado o problema do hermetismo desse sistema processual, pois abordado de maneira a discutir sua matriz constitucional e seus fundamentos jurídicos. Portanto, o que poderia se assemelhar a um sistema 
desconectado, por possuir normatização em várias legislações, passa a ser interpretado como um instrumento integrado e que se movimenta para assegurar direitos que não pertencem a apenas uma pessoa, mas à sociedade.

\section{REFERÊNCIAS}

ALFREDO, Luciana Romaneli Rodrigues e BALEOTTI, Francisco Emílio. A sentença coletiva e a efetividade dos direitos transindividuais. Revista Jurídica Cesumar, Vol. 12, No 2, 2012.

BELLINETTI, Luiz Fernando; SOUZA, Raíssa Fabris. Obstáculos para a efetividade da tutela de direitos transindividuais por entidades sindicais em prejuízo ao efetivo acesso à justiça. Revista Cidadania e Acesso à Justiça, Florianópolis, SC, v. 5, p. 1-17, 2019.

DIDIER JUNIOR, Fredie; ZANETI JUNIOR, Hermes. Curso de Direito Processual Civil: processo coletivo. 9. ed. Salvador: JusPodivm, 2014.

HACHEM, Daniel Wunder. A dupla titularidade (individual e transindividual) dos direitos fundamentais e econômicos, sociais, culturais e ambientais. Revista de Direitos Fundamentais e Democracia, v. 14, n. 14, Curitiba, p. 618-688, jul./dez. 2013.

NEVES, Daniel Amorim Assumpção. Manual de processo coletivo. São Paulo: Método, 2016.

SANTOS, Enoque Ribeiro dos. Processo coletivo do trabalho. 2. ed., rev., atual. e ampl. Rio de Janeiro: Forense, 2018.

ZAVASCKI, Teori Albino. Processo coletivo: tutela de direitos coletivos e tutela coletiva de direitos. Tese (Doutorado Programa de Pós-graduação em Direito) Faculdade de Direito da Universidade Federal do Rio Grande do Sul, Porto Alegre, 2005.

Enviado: Dezembro, 2021. 
Aprovado: Dezembro, 2021. 